\title{
Analysis of Mozambican Elementary Mathematics Textbooks Compared with Japanese Textbooks Focusing on Tasks and Exercises Related to the Real World
}

\author{
Satoshi Kusaka \\ Graduate School for International Development and Cooperation, Hiroshima University \\ 1-5-1 Kagamiyama, Higashi-Hiroshima City, Hiroshima, 739-8529, Japan \\ Tel: 81-90-9145-7153Ｅ-mail: kusaka@ksm.world
}

Received: February 30, 2020

Accepted: March 22, 2020

Published: April 20, 2020

doi:10.5296/gjes.v6i1.16032

URL: https://doi.org/10.5296/gjes.v6i1.16032

\begin{abstract}
The importance of sociocultural perspective in curriculum emphasized in the context of Sustainable Development Goals (SDGs). Textbook has a strong relation of all three types, intended, implemented and attained curriculum. Therefore, analyzing sociocultural features of the textbooks leads to improving quality of education in the context of SDGs. This study aims to clarify the pertinent characteristics of Mozambican elementary mathematics textbooks from a sociocultural perspective (in comparison to Japanese ones) by focusing on how they treat 'real-world' mathematics. The following four perspectives are discussed: (1) Proportion of the tasks related to the real world via the introduction of new learning content (2) Proportion of exercises related to the real world (3) Categorization of the situation of the tasks and exercises related to the real world. As a result, we found that there are few problems which are related directly to the real world in the Mozambican elementary mathematics textbooks. The content of the problems related to the real world are about the tax system and salaries, which means students are given opportunities to view and think mathematically about their social system right from the elementary school age. In addition, various exercises related to social science topics are contained to help students to understand and hand down Mozambican culture.
\end{abstract}

Keywords: Mathematics curriculum, Textbook, Sociocultural perspectives, Mozambique 


\section{Introduction}

Children will voluntarily continue learning if they understand what they are studying and find it interesting. Many teachers and researchers have recognized that textbooks are fundamental for teaching and learning, while they are also the most important resource for influencing both teachers and children (e.g., Hirsch, 2007; Weiss et al., 2002). To ensure quality education, the teachers, children, and teaching materials must interact synergistically (Iwasaki, 2008), and therefore, textbook quality is crucial for the teachers' capacity improvement. UNESCO (2015) emphasizes the same position. That is, textbooks are one of the important factors that create high-quality teaching and learning. They further promote research to boost the quality of textbooks and encourage the distribution of one textbook per subject to each student.

When looking at developing countries, Content in textbooks are often taught as they are due to insufficient teaching materials other than textbooks and the lack of teachers' pedagogical content knowledge. Textbook quality, thus, in developing countries has a larger effect on implementation and achievement of curriculum than in developed countries. The SDGs are challenging to improve the quality of education, and improving textbook quality is a vital initiative directly connected to this objective. World Bank (2015) argued only distributing large number of textbooks in African countries, and although, the number of students possessing textbooks is increasing, their academic levels are not, but distributing suitable textbooks to students is necessary to increase their academic abilities. The review of African textbooks in terms of suitability has shown that many are English and French textbooks created by British and French companies that are inappropriate content-wise and have little relevance to African cultures and languages (Alidou, 2004). UNESCO (2014) has noted that content matching a region's culture and communities, as well as responding to its genders, cultural diversity, and degree of environmental preservation, forms a condition for the suitability of a textbook. In recent years many African countries have created textbooks that suit their own needs (Fredriksen \& Brar, 2015), although many continue using those imported from other countries. The latter state of affairs led to the mathematics texts of some African countries to have inappropriate sociocultural as well as mathematical content.

Mozambique's mathematics textbooks are examined here by comparing and analyzing them from a sociocultural perspective. As a result, some insights may be found that could guide improvements in addressing these critiques and enhance educational quality as outlined in the SDGs. This study aims to clarify the pertinent characteristics of Mozambican elementary mathematics textbooks from a sociocultural perspective in comparison to Japanese textbooks by focusing on how they treat 'real-world' mathematics

\section{Research Questions}

We address two research questions:

(1) How many tasks and exercises related to the real world are contained in Mozambican and Japanese mathematics textbooks?

(2) What kind of tasks and exercises related to real world are contained in Mozambican and 
Japanese mathematics textbooks?

\section{Theoretical Background}

This section aims to show the theoretical background of the reason why we can obtain suggestions for improving the quality of education in Mozambique and also to improve the quality of education in the context of SDGs by comparing Mozambican mathematics textbooks to Japanese ones.

\subsection{Relationship between the Three Types of Curriculum and Textbooks}

Textbooks are developed with reference to principles, objectives, learning skills, and learning content and so on, which are noted in syllabus that outline the intended curriculum. Thus, textbooks are the manifestation of the syllabus that constitute a country's fundamental educational approach. This follows the argument that textbooks are the most useful resource for teachers teaching a class, as indicated by evidence (Schmidt et al., 2001) and signifies how textbooks are the primary resource in determining how teachers teach class content. In addition to reports (Reys et al., 2003), it is demonstrated that teachers teach textbook content exclusively, with nearly no content drawn from outside them. Textbooks are thus, directly connected to implemented curriculum and fulfill an important role in tying intended curriculum to implemented curriculum. Furthermore, Törnroos (2005) has indicated that in international tests of academic skills, such as Trends in International Mathematics and Science Study (TIMSS) and Program for International Student Assessment (PISA), which measure the degree to which implemented curriculum are achieved. A high correlation exists between the correct answers for the type and number of problems in the textbooks and the type and number of problems used for TIMSS and PISA, thereby suggesting a strong relationship between textbooks and attained curriculum. Textbooks are directly and closely related to all three types of curriculum and may have the greatest impact on teaching and learning of any resource.

\subsection{Argument on Elementary Mathematics Textbooks in Sub-Saharan Africa}

According to previous studies on elementary mathematics textbooks in Sub-Saharan Africa, various researchers pointed out the incompatibility with the sociocultural perspective of the country and low relevance between mathematics syllabus in the country and the textbooks. For example, Namukasaa et al. (2010) mentioned that majority of the textbooks in Uganda adopt British and American modern mathematics approaches to East African and African curriculum, therefore, fewer real-life examples appear in the textbooks, and the high frequency of definitions, summary and remember notes, and revision exercises is notably high. Furthermore, some content are repeated at the two grade levels therefore the numbers of chapters or sub-chapters are large. In case of Malawi, Sailors (2012) shows that most instructional materials developed in Malawi do not have the basic attributes of good or high-quality textbooks as described. In addition, he has argued that most instructional materials that support the new curriculum in Malawi are not properly designed, with information errors and content promoting gender bias. In Zambia, Nakawa (2012) pointed out that ideal objectives in the syllabus were not always reflected at the textbook level. The 
objectives in mathematics education advocated for the ability of communication, however in concerning the textbook development and distribution in Sub-Saharan Africa, Bethell, G. (2016) mentioned that the textbooks have to be the right ones, and determining whether a textbook is effective in the teaching of mathematics that requires systematic evaluation in advance of publication. Therefore, ministries of education should subject all proposed textbooks to a comprehensive evaluation by trained reviewers. In order to obtain suggestions to solve the above challenges, basic research such as comparing the mathematics textbook focusing on the tasks and problems is very meaningful.

\subsection{Significance of Comparing Mathematics Textbooks Focusing on Real -World Problem}

In Education for All, (EFA), curriculum innovation failures were pointed out as a reason for stagnation of the quality of education. Additionally, in the Incheon Declaration, carrying forward the thrust of EFA and declaring commitments in education out to 2030, there is a clear call for the reassessment of curriculum to ensure quality education, including skills, competency, values, culture, and knowledge. The goal would be to improve education quality and reexamine curriculum from sociocultural perspectives of competency, values, and culture. The declaration reiterates Goal 4 of the SDGs and sets out aims to 2030. In the field of mathematics education, the 5th International Congress on Mathematical Education held in 1984 set research goals that addressed Mathematics for All, calling for new conceptualizations of mathematics curriculum that relate to the sociocultural reality of developing countries, ethnic minority, gender and so on (Damerow et al., 1984). Nebres (1988) indicated that the uniformity of mathematics curriculum does not fully reflect the needs of the country and in many cases many developing countries borrow the curriculum made for elites in developed countries. Even in recent years, Rosa and Gavarrete (2016) pointed out that it is important to discuss a cultural relevance into the mathematics curriculum in order to help educators to acknowledge the relationship between cultural and school mathematical knowledge. The sociocultural factors of mathematics curriculum have been continuously under debate. This suggests that the universality of mathematics academy and the particularities were fostered by individual ethnicities and cultures, which initially appeared to be irreconcilable which must be incorporated into mathematics education. The issues were proposed more than 30 years ago and still remains with us today. While the generality of mathematics cannot be ignored, the issue of classes addressing it remains a problem that hinders the elevation of the quality of education today, just as was the case in previous years. Mathematics is centrally necessary because it has a role in carrying on a country's culture (Baba et al., 2012), and it also affects the construction of sounder democracies and contributes to the development of society and culture. If textbooks are the primary resource used by teachers when they teach, and a strong relationship exists with all of the three-types of curriculum, the sociocultural features of the textbooks obviously require examination, which could lead to improving them in enhancing mathematics education generally.

Nagasaki (2000) viewed that mathematics learning that uses social context is to be triggered by real world problems. However, the problems are solved as mathematical problems by mathematical modeling, and then they relate back to the real world. He reviewed examples of 
real-world and real-life teaching materials, addressing the connections between mathematics and society or culture. There were 19 types of real-world problems found: a. household life, $b$. school life, c. social life, d. transportation, e. industry, f. natural science, g. social science, h. households, i. technology, j. sports, k. the arts, l. video games, m. puzzles, n. recreation, o. history of mathematics, p. international understanding, q. information, r. the environment, and s. welfare and old age. This study uses these categories to sort problem situations related to the real world in Mozambican and Japanese textbooks and to compare them.

\subsection{Reasons for Comparison with a Japanese Textbook}

There are three reasons why comparing to Japanese textbook is adequate to clarify the characteristics of Mozambican textbook.

Firstly, Japan maintains a high level of learning achievement among its global peers, as judged by TIMSS and PISA. There are several possible reasons for this. Since textbooks are closely related to all three types of curriculum and have the greatest impact on teaching and learning of any resource, the high quality of textbooks used in Japan could be one of those factors.

Secondly, it is suggested that the necessity of using more pages for dealing with social usefulness of mathematics and utility for occupation in the "International Comparative Study on Mathematics Textbooks" by the Ministry of Education, Culture, Sports, Science and Technology (MEXT) (2008) and "Research Project on Improvement and Enhancement of Textbooks" by the National Institute for Educational Policy Research (NIER) (2009). Consequently, they have been improved in subsequent textbook revisions. In addition, the findings of 11-country international comparison of textbooks carried out in 2010 noted that Japanese elementary school mathematics textbooks approached mathematics from the students' own lifestyles and society, while their 2011 versions, in the body and the appendices of their text, had started using pictures and dealing with real-world discussions and problems for both elementary and junior high school (Japan Textbook Research Center, 2012). This implies that the recent revised versions of Japanese textbooks focus even more than Japan's international peers, on real-world topics.

Finally, there is merit in comparing entirely different cultures: Japan and Mozambique. There are, in general, two major categories in comparative education: striving for generalization and striving for differentiation (Imai, 1990). Comparative education that strives for generalization discovers general rules by comparing individual phenomena and applying the rules discovered to individual phenomena while giving weight to the confirmation of general rules. Upon implying that comparative education discovers differences through comparisons, explores historical causes for differences, and generalizes through discovering small-scale differences (Imai, 1990:25). Otsuka (2012) highlighted that comparative education examines various countries, regions, and cultures to find fixed rules and independent patterns, such that generalization and differentiation are complementary. Because education exists in various forms in each culture, there are frequent citations of the significance and difficulty of the comparison of countries across boundaries and fixed areas of culture. However, the comparison of countries from different cultural spheres altogether can be qualified to 
generalization and differentiation, clarify sociocultural characteristics and yield significant information.

\section{Research Methodology}

The discussion in the previous section prompted the use of the following method to conduct comparative analysis of textbooks used by the fifth grade students in Mozambique and Japan. Grade 5 textbooks were chosen because the first half of elementary education in Mozambique continues until that year, and the textbooks used by this highest possible grade were preferred. The textbooks compared were Japan's 'Waku Waku Sansu 5', by Keirinkan, certified in 2014, and Mozambique's 'Descobrir a Mathematica 5', published by Plural Editores, certified in 2014.

\subsection{Ratio of Real-World Problems in Section's Introduction}

The ratio of real-world problems as chapter and section introductions in the two textbooks were examined. In terms of textbook composition, there are instances where the objective was for introductions to construct meaning using problems related to real-world, and then there are those where the focus was on mastering calculation of algorithms. In case of the focus is mastering calculation of algorithms, exercises after the introduction related to the real-world are positioned as tasks to build application skill in those algorithms and definitions. Consequently, this comparison separated problems introducing new learning topics and other exercises in methodology (2). Analyzed problems are story problems and other problems that are related to contexts and involve items that exist in the real world, but not all story problems are real-world problems. The problem "how many multiples of 2 are there in 1 to 100 ?" includes context, but the problem has no connection to the real world. Hence, such problems would fall outside that category in this study.

\subsection{Ratio of Real-World Problems in Exercises}

The problems in exercises were classified into those that were related to the real world and those that were not, and then the ratios of real-world problems were compared between the textbooks. There were cases where larger problems had several smaller ones within them, and the larger problems were counted as one complete problem, and the smaller problems were not considered.

\subsection{Categorizing the Situation of Problems Related to the Real World}

The exercises related to the real world were classified with reference to categories used by Nagasaki (2000). New categories were made to cover for those falling outside Nagasaki's (2000) schema. Duplication was allowed for supporting more accurate analysis. For example, problem situations such as buying groceries were sorted into food ingredients and shopping.

\subsection{Content of Investigative Activities and Socially Open-Ended Problems}

This study approaches investigative activities and socially open-ended problems, which are targets of active study. Baba et al. (2012) defined these as problems with diverse mathematical and social solutions that have the objective of fostering the ability for social 


\section{Ml Macrothink}

Global Journal of Educational Studies

ISSN 2377-3936

2020, Vol. 6, No. 1

judgment through mathematical ways of thinking. Many problems in textbooks appear already in a formulaic structure, even if they are connected to real life. By contrast, the social nature of socially open-ended problems may occur in daily life, which points out to the complex and concrete issues of shared interest for groups requiring realistic and authentic features. Attention to the presence or absence, of socially open-ended problems and a comparison of their content can help elucidate the particularities of textbooks from a sociocultural perspective.

\section{Results and Discussion}

\subsection{Ratio of Real-World Problems in Section's Introduction}

Table 1. Ratio of real-world problems in section's introduction

\begin{tabular}{|c|c|c|}
\hline & Mozambique & Japan \\
\hline Number of Chapters & 16 & 16 \\
\hline Number of Sections & 65 & 40 \\
\hline Number of exercises related to real world (\%) & $25(38.5 \%)$ & $23(57.5 \%)$ \\
\hline
\end{tabular}

Table 1 indicates the ratio of real-world problems among the introductory ones of the chapters and sections. The number of chapters is same in both countries. In the theoretical background, imported textbooks in Uganda has the large number of chapters, however, that is not the case in Mozambique textbooks. Real-world problems were 57.5\% of all introductory problems in Japan and 38.5\% in Mozambique. Thus, it can be said that Japanese textbooks emphasize more constructing meaning in introductory sections, whereas Mozambican ones place a relative emphasis on mastering calculation algorithms and definitions. However, the result shows no statistically significant difference $(p=0.057>0.05)$. In these cases, exercises that come later and are related to the real world should be characterized as tasks utilized to develop the ability in applying those algorithms and definitions.

\subsection{Ratio of Real-World Problems in Section's Introduction}

Table 2. Ratio of real-world problems in all exercises

\begin{tabular}{|l|c|c|}
\hline & Mozambique & Japan \\
\hline Number of exercises & 338 & 344 \\
\hline Number of exercises related to real world (\%) & $90(26.6 \%)$ & $135(39.2 \%)$ \\
\hline
\end{tabular}

Both countries had nearly equal numbers of exercises, though Mozambique's 90 real-world problems made $26.6 \%$ for the number related to real world issues, but Japan's 126 problems made $10 \%$ more of the total- $37.6 \%$. The difference between two countries had statistically significant difference $(\mathrm{p}<0.01)$. 


\section{MlMacrothink}

Global Journal of Educational Studies

ISSN 2377-3936

2020, Vol. 6, No. 1

This signifies the continuing trend of the introductory problems with exercises ones as well. The Mozambican textbook had many more problems focusing on mathematical knowledge and skills than the Japanese book, with a strong knowledge bias and technical focus. Practical competencies related to everyday life are the more focus in Mozambican elementary mathematics syllabus (Ministério da Educação, 2015) such as "To solve problems related to everyday life" and "Apply learning content to daily life" ability. However, the emphasis is placed more on basic knowledge and skills, which means that there is no strong linkage between the textbook and syllabus in Mozambique.

\subsection{Categorizing the Situation of Problems Related to the Real World}

Table 3. Categorization of real-world problems in Mozambican textbook

\begin{tabular}{|c|l|}
\hline Context (No of problem, \%) & \multicolumn{1}{|c|}{ Concrete examples (No. of context) } \\
\hline $\begin{array}{c}\text { Family life } \\
(37,29.4 \%)\end{array}$ & $\begin{array}{l}\text { House (3), Things in the house (1), Garden (5), Food (23), } \\
\text { Cooking utensil (1), Cloths (3) and Floor Plans (1) }\end{array}$ \\
\hline $\begin{array}{c}\text { School life } \\
(12,9.5 \%)\end{array}$ & $\begin{array}{l}\text { Scholastic performance (4), Study (1), School material (5) } \\
\text { and Body (2) }\end{array}$ \\
\hline $\begin{array}{c}\text { Social life } \\
(37,29.4 \%)\end{array}$ & $\begin{array}{l}\text { School building (6), Traffic (3), Market (17), Salary (3), } \\
\text { Savings (1), Time (6) and Calendar (1) }\end{array}$ \\
\hline Agriculture (8, 6.3\%) & Crops, livestock (8) \\
\hline Social science (9,7.1\%) & Geometry (9) \\
\hline $\begin{array}{c}\text { Natural science } \\
(7,5.6 \%)\end{array}$ & $\begin{array}{l}\text { Scale (2), Materials (1), Temperature (1), Plant (2) and } \\
\text { Amount of rain (1) }\end{array}$ \\
\hline Sports (2,1.6\%) & Athletics (1) and Soccer (1) \\
\hline Mathematical history (1,0.8\%) & Mathematical history (1) \\
\hline Industry (8,6.3\%) & Mozambican cloths (8) \\
\hline International understanding & $\begin{array}{l}\text { Trade in African countries (2), Area of African countries (2) } \\
\text { and Monument in the world (1) }\end{array}$ \\
\hline $5,4.0 \%)$ &
\end{tabular}

Table 4. Categorization of real-world problems in Japanese textbook

\begin{tabular}{|c|l|}
\hline Context (No of problem, \%) & \multicolumn{1}{|c|}{ Concrete examples (No. of context) } \\
\hline $\begin{array}{c}\text { Family life } \\
(46,29.7 \%)\end{array}$ & $\begin{array}{l}\text { Things in the house (8), Garden (3), Shopping (19), Food (13), } \\
\text { Cloths (1) and Toys (2) }\end{array}$ \\
\hline $\begin{array}{c}\text { School life } \\
(38,24.5 \%)\end{array}$ & $\begin{array}{l}\text { Study (1), School supplies (7), Body (5), Classroom (1), Physical } \\
\text { ability (2), Subject (2), School activities (17) and Classroom } \\
\text { environment (3) }\end{array}$ \\
\hline $\begin{array}{c}\text { Social life } \\
(21,13.5 \%)\end{array}$ & $\begin{array}{l}\text { Land (4), Building (6), Factory production (1), Transport (9) and } \\
\text { Change of price (1) }\end{array}$ \\
\hline Agriculture (8, 5.1\%) & Crops and livestock (8) \\
\hline Social science & Geometry (7), Prefecture (5), Circumference of a coin (1) and \\
\hline
\end{tabular}




\begin{tabular}{|c|l|}
\hline$(14,9.0 \%)$ & Traditional architecture (1) \\
\hline Natural science $(5,3.2 \%)$ & Scale (1), Sold, liquid and gas (2), Plant (1) and Universe (1) \\
\hline Sports (3,1.9\%) & Marathon (1), Soccer (1) and Basket (1) \\
\hline Art (1, 0.6\%) & Production of gold leaf (1) \\
\hline Play (6, 3.9\%) & Amusement park (5) and Card games (1) \\
\hline Math history (1,0.6\%) & Mathematician (1) \\
\hline Industry (2, 1.3\%) & Metal industry (2) \\
\hline Environment (5, 3.2\%) & Garbage (1) and Automobile fuel consumption (4) \\
\hline Welfare $\cdot$ Health (2, 1.3\%) & Health (1) and Nutrition (1) \\
\hline $\begin{array}{c}\text { International understanding (3, } \\
1.9 \%)\end{array}$ & World trade (3) \\
\hline
\end{tabular}

Nagasaki (2000) gave the template for evaluation of real-world problems. Table 3 presents the results for the Mozambican textbook and Table 4 indicates the results for the Japanese textbook.

The Japanese book had 14 problem situations and 41 examples, the Mozambican book had 10 and 32, respectively. Thus, Japan had 4 more situations and 9 more examples, signifying a wider range of situations. For both countries, the largest number of situations covered family life, and the second largest category was school life for the Japanese textbook and social life for the Mozambican one. The Mozambican textbook had 17 questions on markets and 3 about salaries, and neither of these topics were found in the Japanese textbook. Many Mozambican problems that addressed markets involved wholesale and retail prices of fabric, rice, farm products, and were alike, while salary-related problems covered monthly and annual salaries. These addressed situations that students would encounter but were not realistic for students at their current ages. These were the problems that related to the real world but arguably were not aligned with the experiences of the learners. Mozambique's rate of matriculation into secondary education was low at $42.5 \%$ (Japan International Cooperation Agency 2015). Many of these questions are included in the later grades of elementary school because primary education serves as the foundation for living as a member of society. The incorporation of these in the material used in mathematics classes allows students to think mathematically about real-world social systems they will face in the future. In the Japanese textbook, but not in the Mozambican one, there were environmental and welfare and health issues. These topics have received increasing emphasis in recent years due to the SDGs, they were, however, not covered in the Mozambican textbook.

Social science topics were found in the Mozambican textbook, including the country's geography and industry, such as traditional fabrics. Both these categories were more significantly mentioned in Mozambican textbooks as compared to Japanese ones. The core role of education is to carry culture forward (Baba, et al. 2012), and the use of a large number of these types of situations allows for an emphasis on understanding and handing down a country's culture. 


\subsection{Presence of Socially Open-Ended Problems}

25 people participated in a camp of the children's' association. They have to choose each of the foodstuffs from A to D in the table below and make a curry meal at a cost of less than 10000 yen. Think about the idea of curry and choose the foodstuffs estimating the cost.

\begin{tabular}{|l|l|l|l|}
\hline & \multicolumn{3}{|c|}{ Foodstuffs } \\
\hline A & Beef 5880 yen & Pork 4830 yen & Chicken 3150 yen \\
\hline B & Morimori Vegetable 980 yen & Dokidoki Vegetable 1480 yen & $\begin{array}{l}\text { Wakuwaku Vegetable 1580 } \\
\text { yen }\end{array}$ \\
\hline C & Rice 1850 yen & Brown rice 1980 yen & Nan 2850 yen \\
\hline D & Spicy curry roux 890 yen & Curry roux for children 850 yen & Indian curry roux 980 yen \\
\hline
\end{tabular}

Figure 1. A task in Japanese textbook (Round number)

Specific exercises in Japanese and Mozambican textbooks are considered. First, an exercise in Japanese textbooks is observed (Figure 1). The task requires students to choose a single food item from each of the groups from A to D with a food budget up to 10,000 yen and to make a curry meal using their personal judgment. A socially open-ended problem allows students to work freely within parameters, which creates a diversity of answers. This example is socially open-ended problem because it does not have a single answer but reflects the values of each solver, allowing students to select from among options that align with their own ideas. Some students select from among the options in a way that brings them as close as possible to 10,000 yen; or alternatively, an approach might be to make a meal using the least amount of money. Similarly, other students could select ingredients that best fit their favorite foods or that follow other directives. The primary mathematical objective, which asks students to make calculations using estimates and remain within 10,000 yen, also goes beyond the range of mathematics as personal values influence the answer.

Fill in the blank and answer the following questions.

\begin{tabular}{|l|l|l|l|l|l|}
\hline Types of baggage & A & B & C & D & F \\
\hline Weight & $10.55 \mathrm{~kg}$ & $4.75 \mathrm{~kg}$ & $2.38 \mathrm{~kg}$ & $1.26 \mathrm{~kg}$ & $4.91 \mathrm{~kg}$ \\
\hline Round number (Tenth place) & & & & & \\
\hline Round number (Whole number) & & & & & \\
\hline
\end{tabular}

a) Which is the heaviest bag?

b) Which bags are between $4 \mathrm{~kg}$ and $5 \mathrm{~kg}$ ?

c) You have to pay additional fee when checking in more than $20 \mathrm{~kg}$. If you check in all the baggage, for how many kilograms do you have to pay in this case?

Figure 2. A task in Mozambican textbook (Round number) 
Next, a question in Mozambican textbooks is addressed. The Mozambican textbook did not have a single socially open-ended problem, problems that had the same approximate number calculations as the Japanese textbook were examined and compared to Japanese examples.

These problems were found in unit summaries, coming at the very end of units dealing with approximate numbers. They included problems that required students to complete a table using approximate numbers, followed by three questions. However, each question had only one answer, and the topics students were solving were solely mathematical. For example, "All of (c) is checked baggage that will require an excess baggage surcharge. Since you are only allowed to carry up to $20 \mathrm{~kg}$ of baggage, you must separate your checked baggage from your carry-on bags. Therefore, which bag should be a carry on and which should be checked?" This problem allows various answers, which creates a wider field of operation in a socially oriented open-ended problem that includes personal values and judgments.

\subsection{Characteristics of the Mozambican Elementary Mathematics Textbook}

The following three features were elucidated in the comparison between the Mozambican and Japanese textbooks. The Mozambican textbook had fewer problems related to real-world situations but many asking the students to master fundamental knowledge and skills, with a strong technical focus.

Further, the real-world problems in the Mozambican book, such as those dealing with markets and salaries, were not problems that students of young age would find practical, although they did include many situations the students might later experience in adulthood, thus giving them a chance to mathematically think about real-world social systems quite early. This is presumed to be necessary to instill knowledge and scholastic abilities that will serve students in Mozambican society, where the rate of matriculation into secondary education is low, and students must develop a fixed level of competence with an elementary school education.

Finally, while no investigative activities, or socially open-ended problems were found in the Mozambican textbook, there were complex situations aligned with the real world, which could arguably become socially open-ended problems if their perspective were modified. The syllabus published in 2015 prioritizes practical competency as skills mastery to allow students to use what they learn in daily life. Currently, textbook development based on those syllabuses is being pursued by the Mozambique National Institute for Educational Policy Research. Not only questions with formulas but also real-world problems, investigative activities, and socially open-ended problems are included, making Mozambican textbooks more likely to closely follow the syllabus.

\section{Conclusion}

The objective of this study was to elucidate the characteristics of a Mozambican mathematics textbook from a sociocultural perspective and comparing it with a Japanese textbook by focusing on problem situations related to the real world. In this comparison, the real-world problems introduced in each chapter of each textbook were considered, the ratio of exercise related to the real world were similarly investigated. Categories of problem situations, using 
the work of Nagasaki (2000), were examined.

This research only analyzed textbooks of fifth year elementary school students, and a reasonable number of the characteristics of the Mozambican textbook were found. The analysis did not cover the textbooks of all grade levels. Furthermore, since a comparison was only made with Japanese textbooks, it is necessary to consider textbooks in other countries, using the same method, to objectively illustrate other features. This should be pursued in future research.

\section{References}

Alidou, H. (2004). Medium of Instruction in Post-Colonial Africa. In J. W. Tollefson, \& A. B. M. Tsui. (Eds.), Medium of Instruction Policies: which agenda? whose agenda? (pp. 195-214). Erlbaum Publishers.

Baba et al. (2012). Values in Japanese Mathematics Education: A historical development. ZDM Mathematics Education, 44, 21-32. https://doi.org/10.1007/s11858-012-0406-1

Bethell, G. (2016). Mathematics Education in Sub-Saharan Africa: Status, Challenges, and Opportunities. Washington DC: World Bank. https://doi.org/10.1596/25289

Damerow et al. (1984). Conclusions drawn from the experience of the New Mathematics Movement. Mathematics for All. Division of Science and Technical Environmental Education (Science and Technology Education Document Series No.20), Paris: UNESCO.

Fredriksen, B., \& Brar, S. (2015). Getting Textbooks to Every Child in Sub-Saharan Africa: Strategies for Addressing the High Cost and Low Availability Problem. Directions in Development Human Development. Washington, DC: World Bank. https://doi.org/10.1596/978-1-4648-0540-0

Hirsch, C. R. (2007). Perspectives on the design and development of school mathematics curricula. Reston: National Council of Teachers of Mathematics.

Imai, S. (1990). Hikakukyouikugakuhouhouron ni kansuru ichi kousatsu - Ippanka shikou to saika shikou wo jikutoshite [A Study on Methodology of Comparative Education: Based on Generalization and Differentiation]. Bulletin of the Japan Comparative Education Society, 16, 19-29. https://doi.org/10.5998/jces.1990.19

Iwasaki, H. (2008). Oshierukara manabanai toiu hiniku: zyugyoubunseki no shiten to houhou no kadai [Sarcasm that students do not learn because the teachers teach: Viewpoints and methods of lesson analysis]. School Education, 1096, 12-17.

Japan Textbook Research Center. (2012). Syotoucyuugakko no sansu, suugaku kyokasyo ni kansuru kokusaihikaku cyousa kettka houkokusyo [International comparative survey results on Mathematics textbooks of primary and secondary schools]. Tokyo: Japan Textbook Research Center.

Keirinkan. (2014). Waku waku sansu 5 [Exiting mathematics 5]. Osaka: Shinko shuppansya keirinkan Co., Ltd. 


\section{Macrothink}

Global Journal of Educational Studies

ISSN 2377-3936

2020, Vol. 6, No. 1

Langa, H., \& Paulo, L. N. (2014). Descobrir a Matematica 5. Plural Editores, Maputo.

MEXT. (2008). Kyokasyo no kaizen, jujitsu nikansuru kennkyu houkokusyo (Sansu): Heisi18,19 nendo monbukagakusyo itaku jigyo kyokasyo no kaizen, jyujitu ni kansuru kenkyu jigyou [Report on improvement and enhancement of textbooks (Mathematics): Project entrusted by MEXT]. Tokyo: MEXT.

Ministério da Educação. (2015). Programas do Ensino Primário Língua Portuguesa, Matemática e Educação Física. Mozambique, Ministério da Educação.

Nagasaki, E. (2000). Sansu, sugakuka ni okeru sougoutekina gakusyu [Comprehensive learning in mathematics]. Tokyo: NIER.

Nakawa, N. (2012) Linkage between Mathematics syllabus and textbooks in the republic of Zambia. Tokyo Future University Bulletin, 5, 91-97

Namukasa, I. K., Quinn, M., \& Kaahwa, J. (2010). School mathematics education in Uganda: Its successes and its Failures. Procedia. Social and Behavioral Sciences, 2(2), 3104-3110. https://doi.org/10.1016/j.sbspro.2010.03.473

Nebres, B. F. (1988). School Mathematics in the 1990's: Recent Trends and the Challenge to the Developing Countries. Proceedings of the Sixth International Congress on Mathematical Education, 13-27.

NIER. (2009). Dai 3 ki kagaku gizyutsu kihon keikaku no follow up rikakyouiku bubun ni kakaru cyousakenkyu [Follow-up of the third science and technology basic plan related to science and mathematics education]. Science and Technology Promotion Coordination Fund Research Report. Retrieved June 14, 2018, from NIER Web site: http://www.nier.go.jp/seika_kaihatsu/risu_1_ikkatu.pdf

Otsuka, Y. (2012). Hikaku kyouiku gaku [Comparative education]. Japan Comparative Education Society.

Reys, R., Reys, B., Lapan, R., Holliday, G., \& Wasman, D. (2003). Assessing the impact of standards-based middle grades mathematics curriculum materials on student achievement. Journal for Research in Mathematics Education, 34(1), 74-95. https://doi.org/10.2307/30034700

Rosa, M., \& Gavarrete, M. E. (2016). Polysemic interactions between ethnomathematics and culturally relevant pedagogy. In M. Rosa, U. D’Ambrosio, D. C. Orey. L. Shirley, W. V. Alangui, P. Palhares, \& M. E. Gavarrete (Eds.), Current and future perspectives of ethnomathematics as a program (pp. 23-30). ICME13 Topical Surveys. London, England: Springer Open. https://doi.org/10.1007/978-3-319-30120-4

Sailors, M. (2012) Complementary Reading Material Development: Accomplishments, Successes and Challenges of the Read Malawi Programme. Botswana Journal of African Studies (Special Issue on Literacy), 26, 171-186.

Schmidt, W. H., McKnight, C. C., Houang, R. T., Wang, H., Wiley, D. E., Cogan, L. S., et al. 


\section{Macrothink}

Global Journal of Educational Studies

ISSN 2377-3936 2020, Vol. 6, No. 1

(2001). Why schools matter: A cross-national comparison of curriculum and learning. San Francisco: Jossey-Bass.

Seah, W. T., \& Wong, N. Y. (2012). What student value in effective mathematics learning: a 'Third Wave Project' research study. ZDM, The international Journal on Mathematics Education, 44, 33-43. https://doi.org/10.1007/s11858-012-0391-4

UNESCO. (2014). Textbooks and Learning Resources: Guidelines for Developers and Users. Paris: UNESCO.

Weiss, I. R., Knapp, M. S., Hollweg, K. S., \& Burrill, G. (Eds.) (2002). Investigating the influences of standards: A framework for research in mathematics, science, and technology education. Washington: National Academy Press.

World Bank. (2015). Getting Textbooks to Every Child in Sub-Saharan Africa Strategies for Addressing the High Cost and Low Availability Problem. Washington DC: World Bank.

\section{Copyright Disclaimer}

Copyright for this article is retained by the author(s), with first publication rights granted to the journal.

This is an open-access article distributed under the terms and conditions of the Creative Commons Attribution license (http://creativecommons.org/licenses/by/3.0/). 